Tema: Solidificação / Lingotamento

\title{
REDUÇÃO DE ALARMES DE ROMPIMENTO DE PELE EM AÇOS ALTO ALUMÍNIO NA ACIARIA DA USIMINAS, USINA DE IPATINGA*
}

Alexandre de Freitas Gomes de Mendonça ${ }^{1}$ Fábio Loureiro Moreira ${ }^{2}$ Fagner de Carvalho Oliveira ${ }^{3}$ Pedro Henrique Coelho Soares ${ }^{4}$

\section{Resumo}

O sistema de detecção de rompimento de pele monitora a estabilidade da transferência de calor no molde. Quando é observado desvio de temperatura no molde, esse sistema aciona um alarme e reduz a velocidade de lingotamento para evitar um possível rompimento de pele. Durante a redução de velocidade, alguns aços podem sofrer alteração dimensional e agarramento de placa no veio, podendo ocasionar a interrupção da série. O aço ultrabaixo carbono com alto teor de silício e alumínio, aplicado a indústria elétrica, apresenta esse comportamento. Para melhorar a estabilidade de lingotamento reduziu-se $10 \%$ do teor de alumínio no aço. Em termos práticos, o que se observou foi a melhora na estabilidade operacional, pela redução de aproximadamente $83,7 \%$ dos alarmes falsos de rompimento de pele. A adequação do projeto de liga do aço não alterou as suas propriedades eletromagnéticas.

Palavras-chave: Lingotamento; Alarme de rompimento; Alumínio.

\section{ALARM REDUCTION ON BREAKOUT IN HIGH ALUMINIUM STEEL AT USIMINAS STEELMAKING SHOP, IPATINGA WORKS}

\begin{abstract}
The breakout detection system monitors the stability of heat transference in the mould. When temperature deviation is observed in the mould, the system triggers an alarm and reduces the casting speed to avoid possible disruption of skin. During speed reduction, some steel quality may suffer shaping modification and bulging, which can cause the sequence interruption. The ultra low carbon steel with aluminum and silicon, applied to the electrical industry, presents this behavior. In order to improve the stability of casting aluminum content in the steel was reduced by $10 \%$. In practical terms, it was observed improvement in operational stability and reduction of approximately $83,7 \%$ of false alarms by skin disruption. The steel alloy change did not influence the electromagnetic properties of steel.
\end{abstract}

Keywords: Casting; Breakout alarm; Aluminum.

\footnotetext{
Engenheiro Metalurgista, CQE/ASQ, Gerência Técnica de Aciaria, Usiminas Ipatinga, MG, Brasil. Engenheiro de Produção, Gerência Técnica de Aciaria, Usiminas Ipatinga, MG, Brasil.

Engenheiro Metalurgista, Controle Integrado do Produto de Ipatinga, Usiminas, Membro da ABM, MG, Brasil.

4 Engenheiro de Materiais, Gerência Técnica de Aciaria, Usiminas Ipatinga, MG, Brasil.
}

\footnotetext{
* Contribuição técnica ao 450 Seminário de Aciaria - Internacional, 25 a 28 de maio de 2014, Porto Alegre, RS, Brasil.
} 


\section{INTRODUÇÃO}

O lingotamento contínuo é o método mais eficiente e produtivo para a fabricação de aços na siderurgia. Dentro do contexto da aciaria, esse equipamento é responsável pela solidificação controlada do aço líquido, garantindo o acerto dimensional e o atendimento de qualidade superficial e interna de placa. A Figura 1 ilustra de forma esquemática esse equipamento.

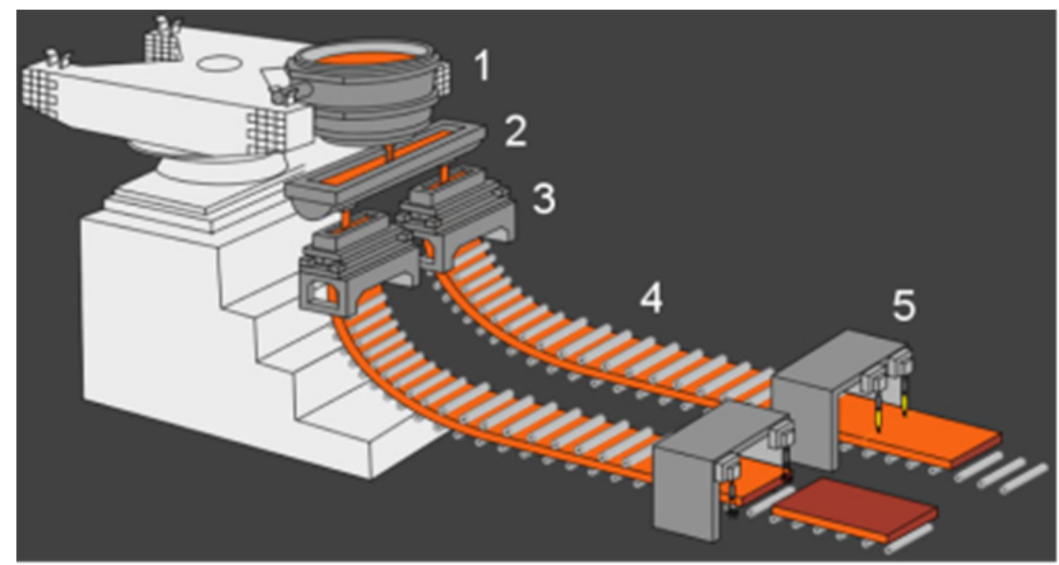

Figura 1. Desenho esquemático da máquina de lingotamento contínuo: (1) Panela; (2) Distribuidor; (3) Molde; (4) Rolos de suporte e extratores e (5) Máquina de corte de placas.

Para iniciar a solidificação, o aço líquido é vazado para o interior de um molde de cobre refrigerado por água. Dentro do molde o aço se solidifica devido ao contato com a parede de cobre, formando uma fina camada sólida denominada pele.

Nesta etapa do processo é utilizado o pó fluxante para evitar o contato da pele de aço com o molde, evitando o atrito excessivo e o colamento, e para um adequado controle do fluxo de calor. Além disso, o molde é oscilante, o que minimiza a tendência do agarramento da pele solidificada na superfície do molde.

Ao sair do molde, a pele deve suportar a pressão ferrostática do aço líquido no interior da placa. Caso contrário, ela se romperá na saída do molde e o aço líquido presente no interior da placa irá danificar os componentes da máquina, tais como, rolos, bicos de spray e outros conjuntos mecânicos. Conforme Barbosa, et al. [1], esse fenômeno do rompimento da pele e vazamento do aço líquido do interior da placa é denominado breakout.

O breakout causa problemas graves à área produtiva, implicando em perda de produção e risco à segurança das pessoas envolvidas. Por sua vez, o breakout pode ser causado por desvios de natureza procedimental, operacional, qualidade das matérias-primas ou por falhas eletro-mecânicas do equipamento. Para reduzir a chance desse evento, o uso de sistema de detecção de breakout ou Breakout Detection System (BDS) é aplicado com grande êxito, desde que bem dimensionados e ajustados aos parâmetros metalúrgicos e do processo. O sistema de detecção de breakout associa o comportamento das temperaturas do molde, medidas por termopares, a um padrão treinado no sistema. Se os critérios de definição do breakout são atingidos, o alarme é disparado e a máquina de lingotamento reduz automaticamente a sua velocidade de operação para uma condição segura. Em geral, indiferente do tipo de aço, busca-se a condição mais estável da velocidade de lingotamento, para o atendimento ao plano de produção e manutenção da qualidade. Em função da redução de velocidade pelo sistema de detecção de breakout, alguns produtos podem ter seu dimensional comprometido.

* Contribuição técnica ao 45 Seminário de Aciaria - Internacional, 25 a 28 de maio de 2014, Porto Alegre, RS, Brasil. 
Em particular, aços micro ligados com alto teor de alumínio e silício apresentam abaulamento excessivo para baixas velocidades de lingotamento, e para condições de severa redução de velocidade pode conduzir a interrupção da série. Para os eventos de redução de velocidade por alarmes considerados verdadeiros, essa ação é imperativa, mas para os alarmes falsos, as reduções são altamente indesejáveis por causar efeitos deletérios à qualidade do aço. Um exemplo de efeito deletério é duplo lingotamento, resultado da sobreposição de peles de aço no molde no momento da redução severa de velocidade, o que normalmente leva a um descarte de produto para eliminar essa imperfeição na placa. Além disso, esse evento também induz a reprogramação do comprimento de placas.

Para alarmes classificados como falsos, o ajuste do sistema de detecção é necessário, mas para isso algumas evidências devem ser levantadas para classificar a natureza do alarme. A análise da regularidade das marcas de oscilação, avaliação da existência ou não de regiões lisas na superfície da placa e/ou marcas que lembram cicatrizes fazem parte do processo de investigação da veracidade do alarme. Esse julgamento busca medir a qualidade da resposta do sistema de detecção de breakout e, se necessário, propor ajustes para aumentar a sua eficiência de detecção.

Neste contexto, o presente trabalho discute as ações que conduziram a uma menor ocorrência de alarmes falsos durante a fabricação de aços ultrabaixo carbono com altos teores de alumínio e silício, destinados à indústria elétrica.

\section{MATERIAL E MÉTODOS}

Para aferição e garantia de um desempenho satisfatório do sistema de detecção de breakout, é considerada boa prática a verificação de placas com alarme. Em função do tipo de alarme acionado, a redução de velocidade de lingotamento apresenta níveis de severidade distintos. As placas afetadas pelos alarmes com maior severidade são desviadas para corte devido ao duplo lingotamento e efeito deletério a qualidade do produto. Contudo antes do corte, essas placas são separadas no pátio de placas para uma inspeção minuciosa pelas equipes de operação e técnica. Em linhas gerais, a equipe envolvida classifica o alarme da placa em verdadeiro ou falso, em função de uma sequência de métodos padronizados. No momento do alarme faz-se a associação da distância lingotada na máquina e a posição relativa do alarme na placa para favorecer a identificação e julgamento do desvio.

Em particular, um aço ultrabaixo carbono com alto teor de alumínio e silício apresenta um comportamento diferenciado quanto a estabilidade operacional do lingotamento e acerto dimensional. Historicamente esse aço apresenta alarmes de breakout com reduções de velocidade severas. Para esses aços verifica-se a incidência de 2,0 alarmes por corrida.

$\mathrm{Na}$ investigação da causa raiz do alarme, a análise do comportamento da temperatura no termopar do sistema de detecção de breakout faz-se necessária. Por essas temperaturas é possível construir um termograma para análise de tendência de variação de temperatura ao longo da face. A Figura 2 ilustra um termograma e sua respectiva escala de gradiente de temperatura superficial.

\footnotetext{
* Contribuição técnica ao 45 Seminário de Aciaria - Internacional, 25 a 28 de maio de 2014, Porto Alegre, RS, Brasil.
} 


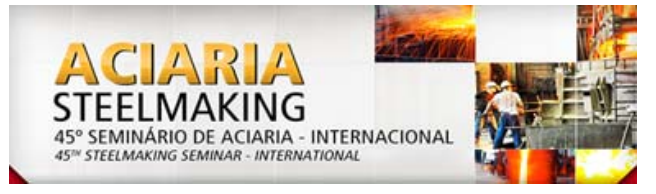

(a)
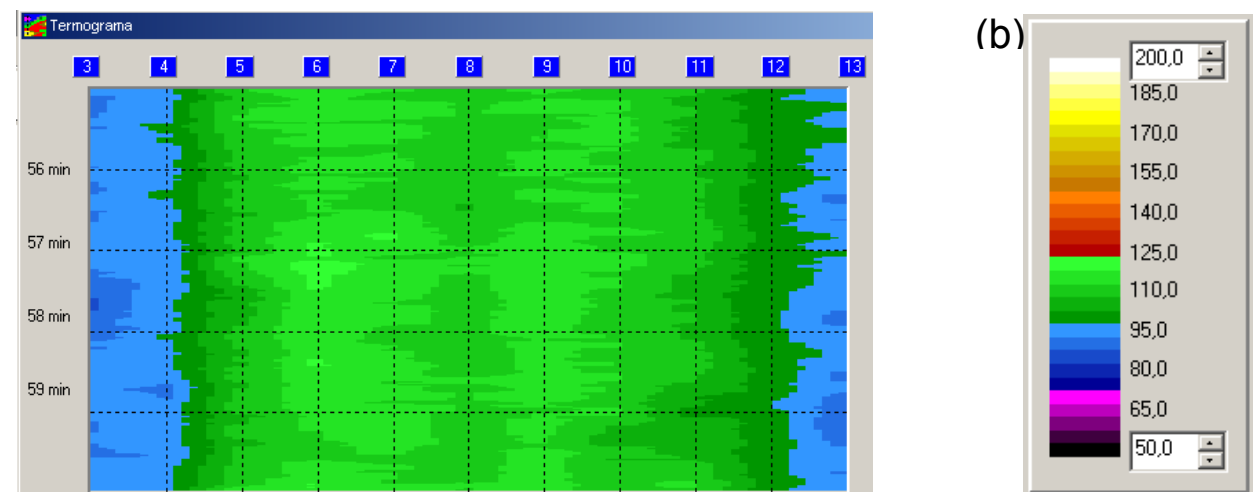

Figura 2. (a) Termograma da face larga do molde, e (b) escala de temperatura superficial.

Nesse termograma é possível identificar pontos ou regiões quentes na superfície da pele de aço no molde e correlacioná-los a uma região específica na placa de alarme durante a análise de campo.

Durante a investigação, constatou-se que quando o teor de alumínio obtido estava próximo ao limite superior da faixa de especificação, a chance da ocorrência do alarme era favorecida e, de forma análoga, quando o teor de alumínio no material se mostrava próximo a faixa inferior, a ocorrência de alarmes de breakout reduzia. Com base nesse fato buscou-se uma redução de $10 \%$ no teor de alumínio no aço, sendo o equivalente a eliminar a região do teor de alumínio de maior probabilidade da ocorrência do alarme. Para o desenvolvimento dessa redução no teor de alumínio, a equipe de desenvolvimento de produto foi diretamente envolvida para avaliação de impactos e viabilidade técnica.

\section{RESULTADO E DISCUSSÃO}

Para a avaliação da melhoria da lingotabilidade foram acompanhadas 110 corridas, sendo 80 corridas com redução de teor de alumínio proposta e 30 corridas com o teor de alumínio original, e registrado número de alarmes das respectivas corridas. A resposta do sistema de detecção de breakout pode ser verificada na Figura 3.

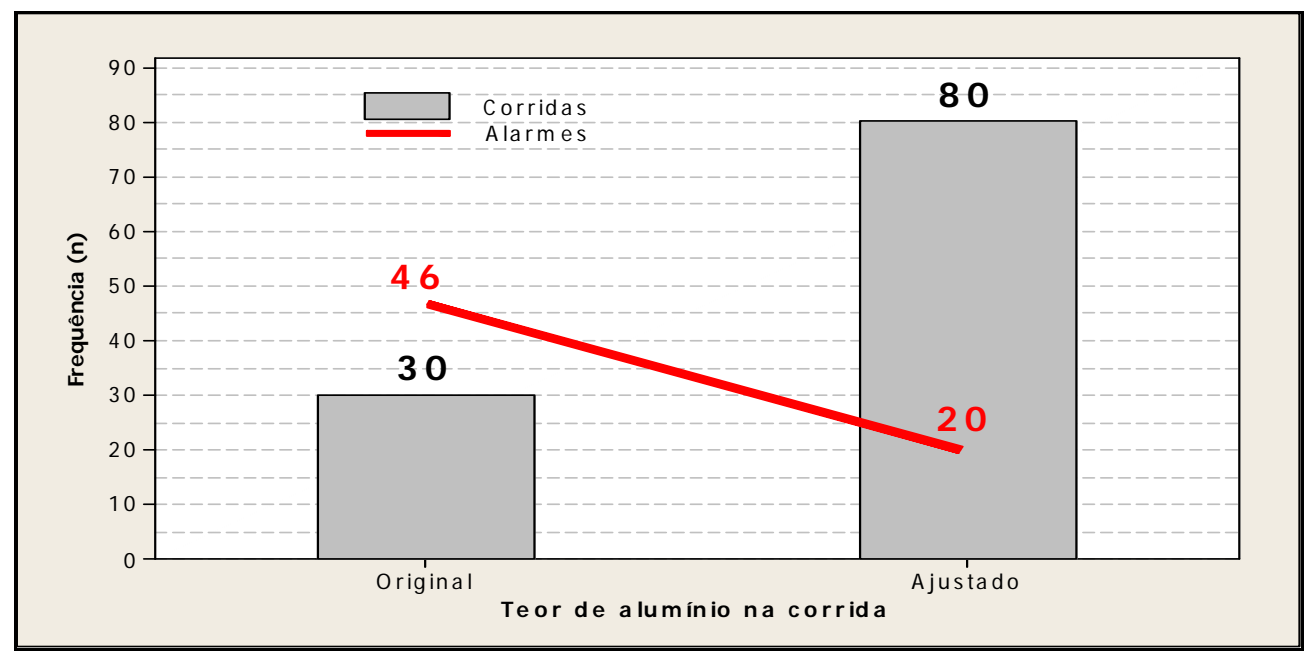

Figura 3. Número de corridas testadas e frequência de alarmes falsos para cada caso.

Em linhas gerais, para a faixa do teor de alumínio original, a média de alarmes foi de 2,00 alarmes por corrida. Após a ação da redução do teor de alumínio, a média foi para 0,25 alarmes por corrida, o equivalente a uma redução de $83,7 \%$ dos alarmes

* Contribuição técnica ao 450 Seminário de Aciaria - Internacional, 25 a 28 de maio de 2014, Porto Alegre, RS, Brasil. 


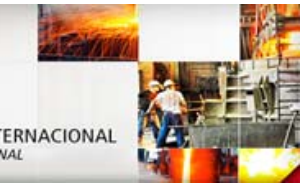

falsos de breakout, refletindo em uma maior estabilidade operacional e garantia de dimensional do produto.

Além dos ganhos comentados anteriormente, a redução controlada do teor de alumínio reduziu o consumo de liga de alumínio em $8,3 \%$ na elaboração do aço de aplicação na indústria elétrica.

Em temos de aplicação, a variável de maior controle é a perda elétrica do material, descrita por Batistela, et al. [2], que é influenciada pela composição química do aço. A Figura 4 apresenta a tendência geral dessa propriedade ao longo da faixa inferior ajustada até a faixa superior original.

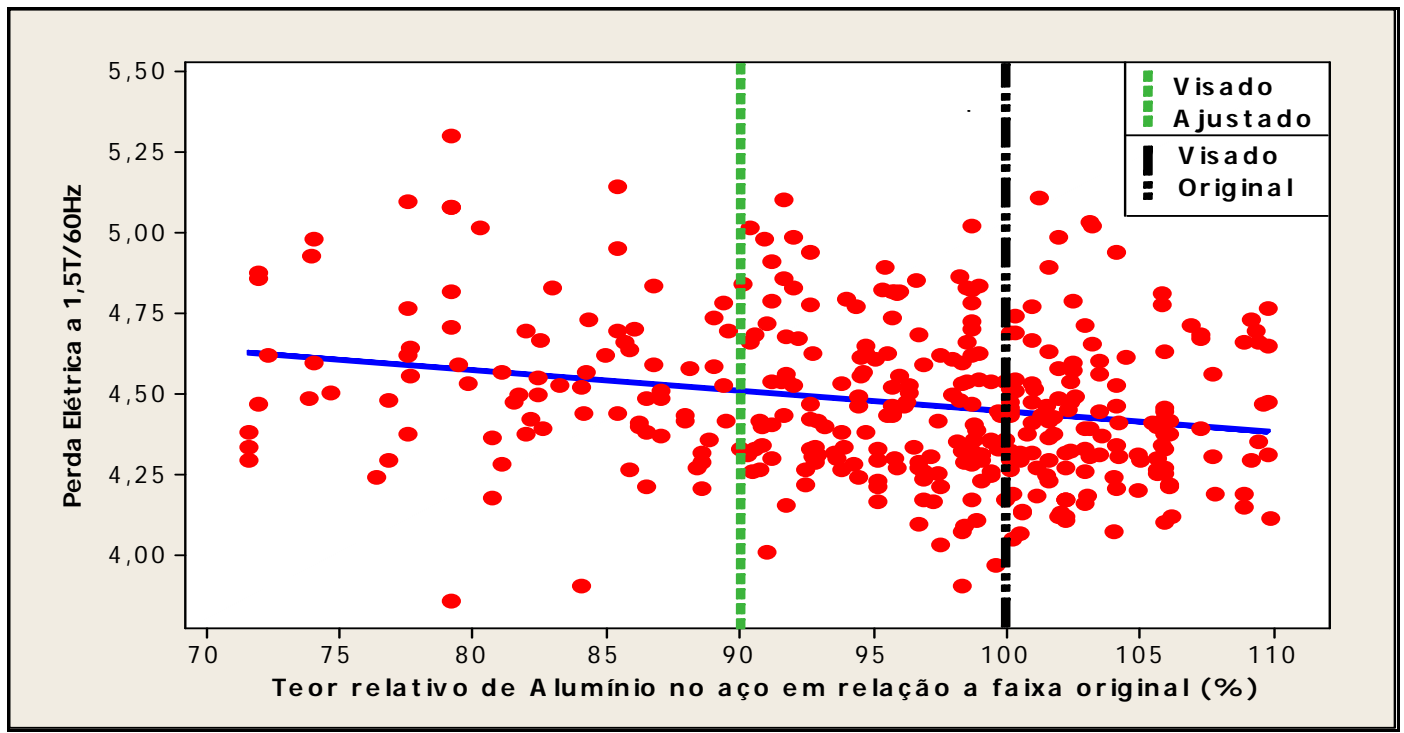

Figura 4. Comportamento da perda elétrica do material a 1,5T a $60 \mathrm{~Hz}$.

A Figura 4 mostra a variação da perda elétrica com a redução do alumínio no aço, contudo Nakayama, et al. [3] demonstra como o controle do teor de outros elementos químicos como o enxofre e o manganês tendem a balancear esse efeito. A Figura 5 ilustra graficamente a comparação da permeabilidade magnética entre a faixa de alumínio original e a faixa com redução de $10 \%$.

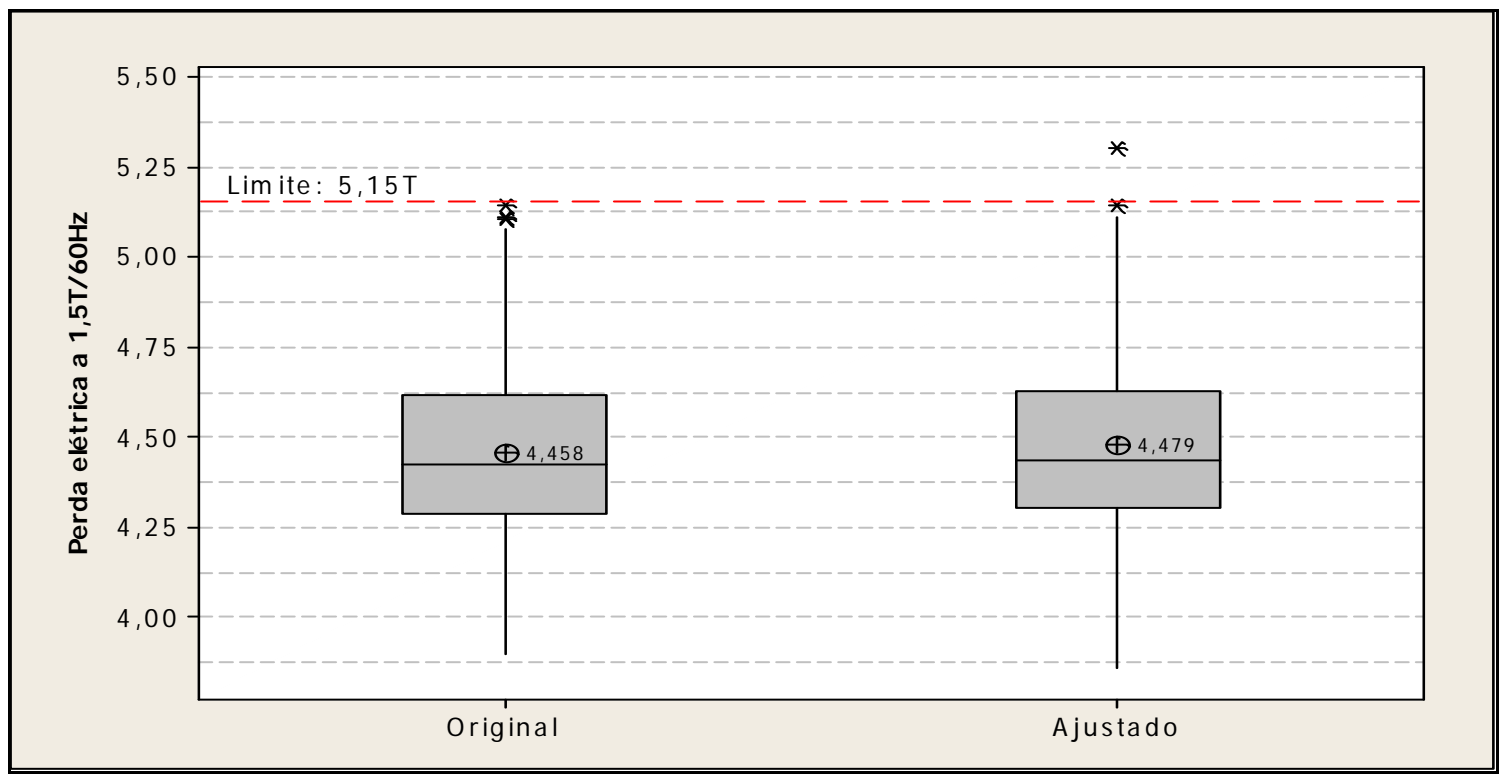

Figura 5. Comportamento da perda elétrica do aço para a faixa original e deslocada de $10 \%$.

* Contribuição técnica ao 450 Seminário de Aciaria - Internacional, 25 a 28 de maio de 2014, Porto Alegre, RS, Brasil. 
A seguir será apresentado o resultado do teste de hipótese supondo igualdade entre as médias e as variâncias, com nível de significância de 5,0\%.

Intervalo de confiança, 95,0\%:

Diferença entre as médias: - 0,0215 $\pm 0,034$;

Razão das variâncias: $(0,758 ; 1,125)$.

Comparação das médias:

Hipótese nula: $\mu=0$;

T stat $=-1,247$, teste bilateral e P-valor de 0,212.

Comparação das variâncias:

Hipótese $\sigma_{1} / \sigma_{2}=1$;

F stat $=0,924$, teste bilateral e P-valor de 0,431.

Pelo presente resultado estatístico não há evidência amostral para rejeitar a hipótese de igualdade entre os tratamentos e nem para o desvio padrão, para o nível de significância de 5,0\% e teste bilateral, uma vez que o P-valor é uma indicação autossuficiente para essa constatação. Com isso, a ação da redução de $10 \%$ no teor de alumínio não comprometeu o desempenho do produto.

\section{CONCLUSÃO}

A redução do teor de alumínio na liga do aço estudado resultou em uma redução $83,7 \%$ dos alarmes falsos de breakout. Essa redução dos alarmes falsos refletiu em uma maior estabilidade da máquina de lingotamento $e$, por consequência, um melhor acerto dimensional de placa.

O deslocamento da faixa do alumínio não alterou significativamente a permeabilidade magnética do aço, mostrando-se estatisticamente iguais tanto para a média, quanto o desvio padrão.

\section{REFERÊNCIAS}

1 Barbosa DLS, Caminhas WM, Resende FMA, Marçal GHR, Rodrigues FD. Detecção de falhas no processo de lingotamento contínuo utilizando máquina de aprendizado e autômato finito. In: X SBAI - Simpósio Brasileiro de Automação Inteligente; 18 a 21 set. 2011; São João Del Rei, Brasil. p.839-844.

2 Batistela NJ, Carlson R, Sadowski N, Leite JV. Caracterização magnética de lâminas de aço silício e avaliação das perdas no ferro sob vários regimes de indução. Revista controle \& Automação. 2002;13(2):156-164.

3 Nakayama T, Honjou N, Minaga T, Yashiki H. Effects of manganese and sulfur contents and slab reheating temperatures on the magnetic properties of non-oriented semiprocessed electrical steel sheet. Journal of Magnetism and Magnetic Materials. 2001;234:55-61.

* Contribuição técnica ao 450 Seminário de Aciaria - Internacional, 25 a 28 de maio de 2014, Porto Alegre, RS, Brasil. 